\title{
Polymorphisms in IL36G gene are associated with plaque psoriasis
}

Tanel Traks ${ }^{1 *}$ (D, Maris Keermann ${ }^{1,2}$, Ele Prans ${ }^{3}$, Maire Karelson ${ }^{1,2}$, Ulvi Loite ${ }^{1}$, Gea Kõks ${ }^{3}$, Helgi Silm¹,2, Sulev Kõks ${ }^{4}$ and Külli Kingo ${ }^{1,2}$

\begin{abstract}
Background: Plaque psoriasis is a non-contagious skin disease in which characteristic red and flaky lesions result from a dysregulation involving both innate and adaptive immune mechanisms. Several cytokines have been implicated in these processes and lately interleukin (IL)-36 family members have become more recognised among them. Thus far, genetic studies have only investigated IL36RN gene of this family in relation to pustular psoriasis. Since IL36G has previously demonstrated markedly increased levels in plaque psoriasis patients and is linked to IL-23/L-17 axis critical in psoriasis pathology, it was chosen to be the focus of current report.
\end{abstract}

Methods: Eleven SNPs from IL36G region were genotyped in 728 plaque psoriasis patients and 320 healthy control individuals. Allele and haplotype frequencies between patients and controls were assessed by respective association tests. For more specific analyses, the patients were assigned into subgroups according to sex, age of disease onset, occurrence of psoriasis among relatives, seasonal aggravation, arthritis symptoms, body surface area (BSA) scores, and Psoriasis Area and Severity Index (PASI) scores.

Results: The most significant results were obtained with SNPs rs28947206, rs28947207 and rs28947211 that were associated in entire plaque psoriasis analysis (multiple testing adjusted $p$ value $\left(p_{\text {adj }}\right)=0.0054$, $p_{\text {adj }}=0$. 0017 and $p_{a d j}=0.0001$ ) and also several subgroups. The first two of those SNPs were included in the same haplotype block with rs28947205 and rs12328178, and two of the respective haplotypes, CAGC and TGT, provided similarly significant associations ( $p_{\text {adj }}=0.0462$ and $p_{\text {adj }}=0.0047$ ).

Conclusions: The associated SNPs of this study or those in linkage disequilibrium with them could potentially affect the functionality of IL-36y cytokine, which in turn may impact plaque psoriasis pathology. For instance, these variants could influence IL-36y expression or 3D structure, thereby altering its ability to induce chemokine production in keratinocytes and various immune cells. The precise mechanisms of these actions are currently unknown and out of the scope of this study. To conclude, the present genetic association results confirm the proposed role of $\mathrm{IL}-36 \mathrm{y}$ in plaque psoriasis development, with corresponding causal effects to be determined in forthcoming research.

Keywords: Plaque psoriasis, IL36G, Cytokines, SNP, Genetic association study

\section{Background}

Psoriasis is a common non-infectious chronic skin disorder that is associated with considerable physical and social burden $[1,2]$. Its estimated prevalence varies globally and is highest in western countries, where it affects around $2-4 \%$ of the population [3]. The most common form is plaque psoriasis, accounting $90 \%$ of all cases and manifesting as

\footnotetext{
* Correspondence: tanel.traks@ut.ee

'Department of Dermatology and Venerology, University of Tartu, 31 Raja St, 50417 Tartu, Estonia

Full list of author information is available at the end of the article
}

sharply demarcated erythematous plaques covered by silvery lamellar scales. Plaques can be few or extend over larger areas, and can also involve the entire body surface as erythroderma in extreme cases [4]. Concurrently, it has become evident that the effects of psoriasis are not exclusively confined to the skin, a notion supported by the regularly observed associations with different systemic diseases ranging from autoimmune to cardiovascular and psychiatric disorders [5].

Based on the pathological mechanisms that contribute to dermatological symptoms, psoriasis is considered an 
immune-mediated disease. The characteristic lesions develop through a complex interplay between both innate and adaptive immune system components [6]. Genetic research has underscored the crucial role of these interactions by identifying numerous susceptibility loci that contain immune-related genes, providing valuable insights into the pathogenic processes [7]. Central mechanisms can be divided into 1) the cytokine-mediated cross-talk between innate and adaptive immune systems involving tumor necrosis factor $\alpha$ (TNF- $\alpha)$, interferon $\gamma$ (IFN- $\gamma$ ) and interleukin 1 (IL-1); 2) the IL-23/T helper cell 17 (Th17) axis; and 3) the effect of immune reactions on other skin cells [4].

More recently, pro-inflammatory IL-36 family cytokines have emerged as important drivers in psoriasis pathology [8]. All three members of the family, IL-36 $\alpha$, IL-36 $\beta$ and IL-36y, are overexpressed in psoriasis lesional skin [9] and elevated IL-36 $\alpha$ in a transgenic mouse model was shown to induce psoriasis-like symptoms [10]. Noticeably, the increased levels of IL-36 $\alpha$, IL-36 $\beta$ and IL-36y in lesional skin were in good correlation with central cytokines of psoriasis pathology: IL-22, IL-17A, TNF- $\alpha$ and IFN- $\gamma$ [11]. This suggests an inter-regulation that was further affirmed by intradermal injection of IL-36 $\alpha$ into wild-type FVB mice, which lead to the increases of IL-36 $\alpha$ itself, IL-17A, IL-23, TNF- $\alpha$ and IFN- $\gamma$ mRNA [12]. On the other hand, injections of TNF- $\alpha$, IL-17A, IL-23, IFN- $\gamma$, and IL-22 or their combinations induced IL-36 $\alpha$, IL-36 $\beta$ and IL-36 $\gamma$ [12]. All of this indicates that IL-36 cytokines synergize with prominent IL-23/Th17 axis in producing the psoriasis symptoms [13]. Additionally, cathelicidin (LL37) functions as an alarmin by responding to stimuli such as infection and wounding in the skin and displays aberrant expression in psoriasis, rosacea, and other inflammatory skin disorders [14-16]. Considering its proposed triggering role in psoriasis [17], it is interesting to note that LL37 increases IL-36y protein expression and release from keratinocytes, that both LL37 and IL-36y are coordinately abundant in psoriasis epidermis and IL-36y in turn upregulates the production of chemokine (C-X-C motif) ligand 1 (CXCL1), CXCL8, CXCL10 and CCL20 in keratinocytes [18]. Finally, from the genetics standpoint, only IL36RN gene (encodes an antagonist IL-36Ra for common IL-36 family receptor - IL-36R) polymorphisms have been analyzed to date, yealding associations with pustular form of psoriasis [19-21].

In accordance with the findings described above, our plaque psoriasis whole transcriptome analysis detected an up-regulation of IL36A, IL36G and IL36RN gene expression in psoriasis patients [22]. This was further confirmed in a more detailed report, wherein IL36G and IL36RN demonstrated the most pronounced changes and IL-36y was also shown to be markedly increased on a protein level [23]. To expand on the described observations, selected polymorphisms of the most promising candidate, IL36G, were genotyped in order to determine their possible associations with psoriasis susceptibility.

\section{Methods \\ Study sample}

The plaque psoriasis patients were recruited at the Department of Dermatology, University of Tartu, Estonia as described previously [24]. All were Caucasian, unrelated, living in Estonia and had a clear clinical diagnosis of plaque psoriasis $(n=728$, age range $18-89$ years). The control group included healthy unrelated Caucasians $(n=320$, age range $18-71$ years) without a personal or family history of psoriasis. They were enrolled from medical students, health care personnel and patients presenting at the dermatological outpatient clinic with mild expression of either facial teleangiectasis or skin tags. To conduct additional analyses, the patients were assigned into different subgroups according to specific subphenotypes. The early onset group consisted of cases where the symptoms appeared at or before 40 years of age $(n=551)$ and late onset when they appeared after 40 years of age $(n=177)$. Familial group included those that had psoriasis among relatives $(n=315)$ and the absence of it designated sporadic cases $(n=410)$. Three groups were formed according to the body surface area (BSA) scores: BSA $\leq 10(n=182)$, BSA $11-30(n=258)$ and BSA $\geq 31 \quad(n=285)$. Likewise, three groups were formed according to the Psoriasis Area Severity Index (PASI) scores: PASI $\leq 10(n=233)$, PASI $11-20(n=225)$ and PASI $\geq 21(n=265)$. Seasonal aggravation of symptoms was used to distinguish the spring-summer $(n=42)$ and fall-winter $(n=533)$ groups. Patients with inflammatory arthritis symptoms formed the PsA+ group $(n=152)$. Finally, male $(n=400)$ and female $(n=328)$ patients were analysed separately against their respective controls $(n=137, n=157)$.

\section{Preparation of genomic DNA and analysis of genetic polymorphisms}

Genomic DNA was extracted from whole blood by standard high-salt extraction method and eleven single-nucleotide polymorphisms (SNPs) were genotyped using the OpenArray Real-Time PCR Platform (Thermo Fisher Scientific, Waltham, Massachusetts, USA). The selected SNPs spanned almost the entire length of IL36G (Fig. 1).

\section{Data analysis}

The Haploview v4.2 program was used for Hardy-Weinberg equilibrium (HWE) calculations in control group and subsequent allelic association and haplotype association tests between groups of patients and controls [25]. The Solid spine of LD algorithm ( D' $^{\prime}$ 0.8) integrated in Haploview v4.2 was applied to define the haplotype blocks and the resulting blocks were used in the haplotype association test. Differences in allele or haplotype frequencies between 


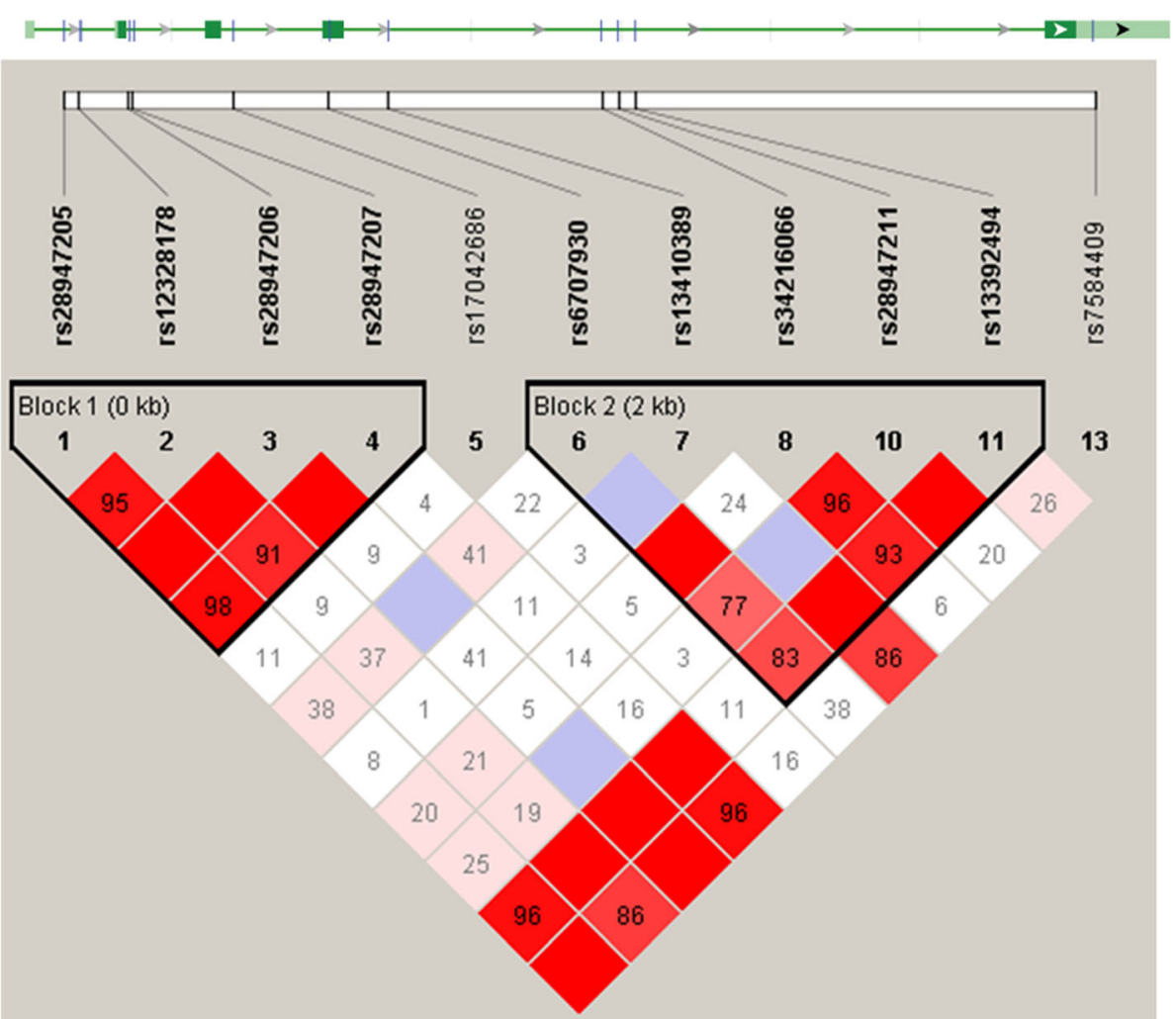

Fig. 1 /L36G gene and genotyped SNPs. The image of LD pattern was generated using the Haploview v4.2 program and black boxes indicate haplotype blocks in entire psoriasis analysis

cases and controls were assessed by chi square test. The statistical significance threshold was set to 0.05 for all tests. The built-in permutation module of Haploview v4.2 was used to correct the $p$ values for errors of multiple testing. Ten thousand permutations were performed, resulting in adjusted $\mathrm{p}$ values $\left(\mathrm{p}_{\text {adj }}\right)$.

\section{Results}

The genotyping procedure provided the genotypes of eleven studied SNPs (Table 1). All were polymorphic and met the inclusion criteria for Hardy-Weinberg equilibrium (Hardy-Weinberg p value $>0.05$ ).

\section{Allelic association analysis}

The strongest allelic associations were obtained with SNPs rs28947206, rs28947207 and rs28947211 (Tables 2 and 3). When analysing the entire psoriasis group, all three remained significant after correcting for multiple testing $\left(p_{a d j}=0.0054\right.$, risk allele odds ratio $(\mathrm{OR}) 14.14,95 \%$ confidence interval (CI) 1.93-103.81; $\mathrm{p}_{\text {adj }}=0.0017$, OR 4.43, CI 1.9-10.3; $\mathrm{p}_{\mathrm{adj}}=0.0001$, OR 4.09, CI 2.04-8.17). In addition, rs28947206 associations withstood the correction in early onset ( $\mathrm{p}_{\mathrm{adj}}=0.0145$, OR 12.68, CI 1.7-94.48), late onset $\left(\mathrm{p}_{\mathrm{adj}}=0.0008\right.$, OR 18.66, CI 2.38-146.4), familial ( $\mathrm{p}_{\mathrm{adj}}=$ 0.003, OR 15.63, CI 2.06-118.7), sporadic $\left(\mathrm{p}_{\mathrm{adj}}=0.0122\right.$,
OR 13.08, CI 1.73-98.96), fall-winter ( $\mathrm{p}_{\mathrm{adj}}=0.0203$, OR 11.98, CI 1.6-89.71), BSA $\leq 10$ ( $\mathrm{p}_{\text {adj }}=0.0207$, OR $12.7 \mathrm{CI}$ $1.56-103.69)$, BSA $11-30\left(\mathrm{p}_{\text {adj }}=0.0015\right.$, OR 16.98 , CI 2.21-130.3), BSA $\geq 31 \quad\left(\mathrm{p}_{\mathrm{adj}}=0.0131\right.$, OR 12.7 CI 1.6398.72), PASI $\leq 10$ ( $\mathrm{p}_{\mathrm{adj}}=0.0133$, OR 12.88 , CI 1.63-102.09), and PASI $\geq 21$ ( $\mathrm{p}_{\mathrm{adj}}=0.0003$, OR 19.01, CI 2.5-144.46) group analyses. Rs 28947207 demonstrated this in all the same groups and also male psoriasis analysis: early onset $\left(\mathrm{p}_{\mathrm{adj}}=0.0036\right.$, OR 4.17, CI 1.76-9.85), late onset $\left(\mathrm{p}_{\mathrm{adj}}=\right.$ 0.0009, OR 5.26, CI 2.05-13.47), familial ( $\mathrm{p}_{\mathrm{adj}}=0.016$, OR 3.83 , CI 1.55-9.47), sporadic ( $\mathrm{p}_{\mathrm{adj}}=0.0006$, OR 4.94, CI 2.07-11.8), fall-winter ( $\mathrm{p}_{\mathrm{adj}}=0.004$, OR 4.15, CI 1.75-9.84), $\mathrm{BSA} \leq 10 \quad\left(\mathrm{p}_{\mathrm{adj}}=0.0358\right.$, OR 3.84, CI 1.45-10.21), BSA $11-30\left(\mathrm{p}_{\text {adj }}=0.0022\right.$, OR 4.62, CI 1.86-11.49), BSA $\geq 31$ $\left(\mathrm{p}_{\text {adj }}=0.0015\right.$, OR 4.67 CI 1.9-11.49), PASI $\leq 10$ ( $\mathrm{p}_{\text {adj }}=$ 0.0351 , OR 3.69, CI 1.43-9.52), PASI $\geq 21$ ( $\mathrm{p}_{\text {adj }}=0.0001$, OR 5.97, CI 2.46-14.5), and male psoriasis ( $\mathrm{p}_{\text {adj }}=0.0191$ OR 12.5, CI 1.7-91.64). Rs28947211 results remained significant in early onset ( $\mathrm{p}_{\mathrm{adj}}=0.0001$, OR 5.08 , CI $2.24-$ 11.48), familial ( $\mathrm{p}_{\mathrm{adj}}=0.0019$, OR 5.88 CI 2.01-17.18), sporadic ( $\mathrm{p}_{\text {adj }}=0.0201$, OR 3.26 CI 1.49-7.14), fall-winter $\left(\mathrm{p}_{\mathrm{adj}}=0.0006\right.$, OR 4.33, CI 1.98-9.47), BSA $\leq 10\left(\mathrm{p}_{\mathrm{adj}}=\right.$ 0.0107, OR 13.21, CI 1.77-98.48), BSA $\geq 31$ ( $\mathrm{p}_{\text {adj }}=0.0421$, OR 3.45, CI 1.39-8.59), PASI $\leq 10$ ( $\mathrm{p}_{\text {adj }}=0.0119$, OR 5.62, CI $1.67-18.91)$, PASI $11-20\left(\mathrm{p}_{\mathrm{adj}}=0.0427\right.$, OR $4.18 \mathrm{CI}$ 
Table 1 Characteristics of studied SNPs

\begin{tabular}{llllll}
\hline SNP & Position & pHW & MAF & Alleles (major/minor) & Feature \\
\hline rs28947205 & $112,978,286$ & 1.0 & 0.021 & C/T & intron \\
rs12328178 & $112,978,391$ & 1.0 & 0.013 & A/G & intron \\
rs28947206 & $112,978,719$ & 1.0 & 0.002 & G/T & intron \\
rs28947207 & $112,978,748$ & 1.0 & 0.011 & C/T & intron \\
rs17042686 & $112,979,417$ & 0.6071 & 0.066 & G/C & intron \\
rs6707930 & $112,980,053$ & 1.0 & 0.012 & C/A & missense (GIn34Lys) \\
rs13410389 & $112,980,446$ & 0.7871 & 0.085 & G/A & intron \\
rs34216066 & $112,981,873$ & 0.1303 & 0.095 & T/C & intron \\
rs28947211 & $112,981,986$ & 1.0 & 0.041 & T/C & intron \\
rs13392494 & $112,982,098$ & 0.175 & 0.464 & C/T & intron \\
rs7584409 & $112,985,157$ & 0.8851 & 0.31 & A/G & 3' UTR \\
\hline
\end{tabular}

pHW - Hardy-Weinberg $p$ value

MAF - minor allele frequency among healthy controls

3' UTR - 3' untranslated region

$1.43-12.24$ ), and female ( $\mathrm{p}_{\text {adj }}=0.0038$, OR 5.51 CI $1.92-$ 15.81 ) groups. The remaining SNPs did not produce significant results after multiple testing correction in the entire psoriasis group, but it did occur in certain subgroup analyses. Namely, rs28947205 remained significant in PASI $\geq 21$ ( $\mathrm{p}_{\text {adj }}=0.0295$, OR 2.73 , CI 1.36-5.48), rs12328178 in $\mathrm{BSA} \geq 31$ ( $\mathrm{p}_{\text {adj }}=0.0483$, OR 3.21, CI 1.35-7.62) and PASI $\geq 21$ ( $\mathrm{p}_{\text {adj }}=0.0019$, OR 4.25, CI 1.82-9.92), and rs34216066 $\left(\mathrm{p}_{\text {adj }}=0.0031\right.$, OR 2.64, CI 1.52-4.59) in female psoriasis analysis. Additionally, SNPs rs6707930, rs13392494 and rs7584409 produced nominal associations in certain subgroups, but none of these withstood the correction.

\section{Haplotype analysis}

The studied SNPs formed two haplotype blocks in the entire psoriasis analysis (Fig. 1). The first block consisted of rs28947205, rs12328178, rs28947206 and rs28947207 and the second block included rs6707930, rs13410389, rs34216066, rs28947211 and rs13392494. The first block had the same composition in all of the subgroups, whereas the second block had the last SNP rs13392494 omitted in early onset and BSA 11-30 analyses. In the case of familial, fall-winter, female and PASI 11-20 groups the second block was split into two, resulting in block 2 consisting of rs6707930 and rs13410389 and block 3 consisting of rs34216066, rs28947211 and rs13392494.

The most significant haplotype associations involved block 1 haplotypes CAGC and TGTT. Both of them withstood the correction for multiple testing in entire psoriasis analysis $\left(\mathrm{p}_{\mathrm{adj}}=0.0462\right.$, OR 0.45 , CI $0.25-0.8$, and $\mathrm{p}_{\mathrm{adj}}=$ 0.0047, OR 8.08, CI 2.01-32.53; Table 4). Further, TGTT associations remained significant in early onset $\left(\mathrm{p}_{\mathrm{adj}}=\right.$ 0.0087, OR 7.8, CI 1.85-32.95), late onset ( $\mathrm{p}_{\mathrm{adj}}=0.0018$, OR 10.49, CI 2.23-49.26), familial ( $\mathrm{p}_{\mathrm{adj}}=0.0031$, OR 8.7, CI 2.07-36.49), sporadic ( $\mathrm{p}_{\text {adj }}=0.0096$, OR 8.5, CI 1.8439.3), fall-winter ( $\mathrm{p}_{\mathrm{adj}}=0.0112$, OR 7.6, CI 1.79-32.23),
BSA 11-30 (padj $=0.0019$, OR 9.54, CI 2.17-41.94), BSA $\geq$ 31 ( $\mathrm{p}_{\text {adj }}=0.0102$, OR 8.55, CI 1.8-40.58), PASI $\leq 10$ ( $\mathrm{p}_{\text {adj }}=$ 0.0235 , OR 7.96, CI 1.62-39.02), PASI $\geq 21$ ( $\mathrm{p}_{\mathrm{adj}}=0.0002$, OR 11.46, CI 2.66-49.46) and male psoriasis ( $\mathrm{p}_{\text {adj }}=0.0544$, OR 15.18, CI 1.17-196.9) analyses. CAGC associations remained significant in late onset $\left(\mathrm{p}_{\mathrm{adj}}=0.0142\right.$, OR 0.35 , CI 0.18-0.68), sporadic ( $\mathrm{p}_{\text {adj }}=0.0183$, OR 0.39, CI 0.210.72 ) and PASI $\geq 21$ ( $\mathrm{p}_{\mathrm{adj}}=0.0029$, OR 0.34 , CI $0.18-0.64$ ) analyses. Block 2 haplotypes did not produce as strong associations in entire psoriasis group and the only result to survive permutation testing involved haplotype CGCC in early onset psoriasis ( $\mathrm{p}_{\mathrm{adj}}=0.026$, OR 0.32 , CI $0.15-0.7$ ). In the case of block 3 , haplotype CCT withstood this correction in familial ( $\mathrm{p}_{\text {adj }}=0.0057$, OR 0.3 , CI $0.15-0.63$ ), fall-winter $\left(\mathrm{p}_{\text {adj }}=0.0019\right.$, OR $\left.0.34, \mathrm{CI} 0.19-0.62\right)$ and female $\left(\mathrm{p}_{\text {adj }}=0.0014\right.$, OR 0.24 , CI $0.11-0.52$ ) psoriasis groups.

\section{Discussion}

Psoriasis develops in a multifactorial process influenced by the immune system, psoriasis-associated genetic susceptibility loci, autoantigens, and various environmental factors [26]. The possible triggers include mild trauma, sunburn, chemical irritants, systemic drugs, occupational risk factors impairing the skin barrier function, and HIV infection [4]. Estimated heritability at $66-90 \%$ is among the highest of all multifactorial genetic diseases, indicating the substantial impact of genetic susceptibility [27, 28]. The major risk loci that have been identified contain genes related to skin barrier functions, IL-23/Th17 axis, nuclear factor- $\mathrm{kB}$ and interferon signaling, and antigen presentation, thereby uncovering pathways behind the disease $[27,29]$. Still, it is estmated that only about $25 \%$ of psoriasis heritability has been accounted for through all genetic discoveries published [30]. 


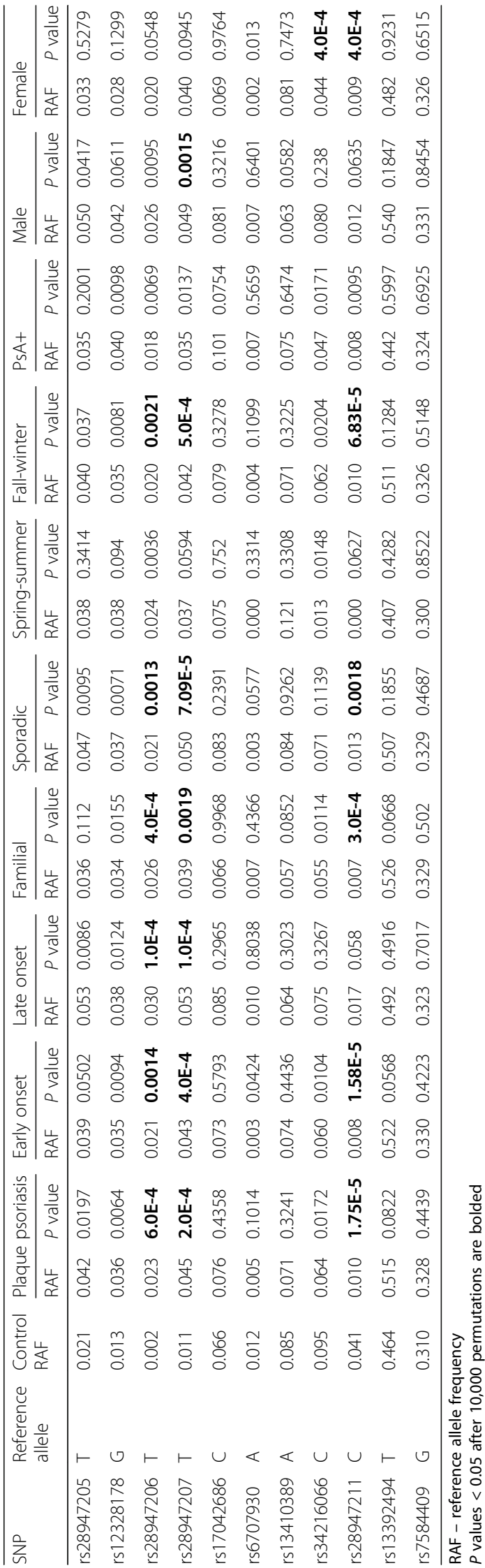


Table 3 Results of allelic association analysis

\begin{tabular}{|c|c|c|c|c|c|c|c|c|c|c|c|c|c|c|}
\hline \multirow[t]{2}{*}{ SNP } & \multirow{2}{*}{$\begin{array}{l}\text { Reference } \\
\text { allele }\end{array}$} & \multirow{2}{*}{$\begin{array}{l}\text { Control } \\
\text { RAF }\end{array}$} & \multicolumn{2}{|c|}{$\mathrm{BSA} \leq 10$} & \multicolumn{2}{|c|}{ BSA 11-30 } & \multicolumn{2}{|c|}{$\mathrm{BSA} \geq 31$} & \multicolumn{2}{|c|}{ PASI $\leq 10$} & \multicolumn{2}{|c|}{ PASI 11-20 } & \multicolumn{2}{|c|}{ PASI $\geq 21$} \\
\hline & & & RAF & $P$ value & RAF & $P$ value & RAF & $P$ value & RAF & $P$ value & RAF & $P$ value & RAF & $P$ value \\
\hline s28947205 & $\mathrm{T}$ & 0.021 & 0.041 & 00799 & 0.045 & 0.0243 & 0.041 & 00504 & 0.036 & 0.1314 & 0.034 & 0.1804 & 0.054 & 0.0032 \\
\hline rs12328178 & G & 0.013 & 0.033 & 0.0344 & 0.033 & 0.0246 & 0.039 & 0.0053 & 0.031 & 0.045 & 0.022 & 0.2429 & 0.051 & $3.0 \mathrm{E}-4$ \\
\hline rs28947206 & T & 0.002 & 0.021 & 0.0023 & 0.028 & $2.0 \mathrm{E}-4$ & 0.021 & 0.0018 & 0.021 & 0.0018 & 0.017 & 0.0075 & 0.031 & $7.38 \mathrm{E}$ \\
\hline rs28947207 & $\mathrm{T}$ & 0.011 & 0.039 & 0.0038 & 0.047 & $3.0 \mathrm{E}-4$ & 0.048 & $2.0 \mathrm{E}-4$ & 0.038 & 0.0039 & 0.036 & 0.0060 & 0.060 & $8.64 \mathrm{E}-$ \\
\hline rs17042686 & C & 0.066 & 0.098 & 0.0834 & 0.062 & 0.8463 & 0.073 & 0.6552 & 0.095 & 0.0982 & 0.071 & 0.7567 & 0.061 & 0.7902 \\
\hline rs6707930 & A & 0.012 & 0.000 & 0.0539 & 0.005 & 0.2288 & 0.008 & 0.5211 & 0.002 & 0.1131 & 0.002 & 0.1145 & 0.009 & 0.6308 \\
\hline rs13410389 & A & 0.085 & 0.056 & 0.1455 & 0.096 & 0.5856 & 0.058 & 0.1116 & 0.071 & 0.4649 & 0.083 & 0.9044 & 0.060 & 0.1548 \\
\hline rs34216066 & C & 0.095 & 0.059 & 0.0642 & 0.073 & 0.2135 & 0.059 & 0.0262 & 0.054 & 0.0175 & 0.084 & 0.5635 & 0.056 & 0.0193 \\
\hline rs28947211 & C & 0.041 & 0.003 & 0.0011 & 0.013 & 0.0093 & 0.012 & 0.0047 & 0.008 & 0.0017 & 0.010 & 0.0047 & 0.013 & 0.0087 \\
\hline rs13392494 & T & 0.464 & 0.508 & 0.2753 & 0.500 & 0.3266 & 0.534 & 0.0452 & 0.519 & 0.1425 & 0.471 & 0.8657 & 0.549 & 0.0159 \\
\hline rs7584409 & G & 0.310 & 0.308 & 0.9415 & 0.317 & 0.8073 & 0.348 & 0.1793 & 0.295 & 0.6002 & 0.303 & 0.8179 & 0.377 & 0.0239 \\
\hline
\end{tabular}

RAF - reference allele frequency

$P$ values $<0.05$ after 10,000 permutations are bolded

It is well established that pro-inlammatory cytokines play a prominent role in pathways leading to psoriasis. For instance, TNF- $\alpha$ released by both $\mathrm{T}$ cells and antigen-presenting cells facilitates the influx of inflammatory cells into lesional skin through induction of adhesion molecules, promotes the synthesis of other pro-inflammatory mediators, and activates dermal macrophages and dendritic cells [31]. Importantly, TNF- $\alpha$ also induces the production of another pivotal cytokine, IL-23, in myeloid dendritic cells [32]. This in turn causes the activation of Th17 cells and the effects of elevated IL-17, including epidermal hyperplasia, epidermal cell proliferation, and leukocyte infiltration into the skin [26]. Similarly to above cytokines, increased expression of IL-36 $\alpha$, IL-36 $\beta$, IL-36 $\gamma$ and IL-36Ra has been detected in psoriasis patients $[9,23]$. Notably, it has been demonstrated that IL-36 can be induced in human keratinocytes by TNF, IL-17, IL-22, and IL-36 itself; and conversely, IL-36 promotes TNF, IL-6 and

Table 4 Results of haplotype analysis in entire psoriasis group

\begin{tabular}{clllll}
\hline Haplotype & Frequency & Controls & Patients & Chi Square & $P$ value \\
\hline Block 1 & & & & & \\
CAGC & 0.957 & 0.976 & 0.948 & 7.9 & $\mathbf{0 . 0 0 4 9}$ \\
TGT & 0.020 & 0.004 & 0.028 & 12.198 & $\mathbf{5 . 0 E - 4}$ \\
TGGT & 0.016 & 0.018 & 0.016 & 0.076 & 0.7831 \\
Block 2 & & & & & \\
CGTTC & 0.493 & 0.509 & 0.486 & 0.88 & 0.3482 \\
CGTTT & 0.359 & 0.327 & 0.374 & 3.745 & 0.053 \\
CATTT & 0.080 & 0.083 & 0.078 & 0.109 & 0.7409 \\
CGCTT & 0.039 & 0.034 & 0.041 & 0.519 & 0.4714 \\
CGCCT & 0.015 & 0.011 & 0.024 & 4.493 & 0.034 \\
\hline
\end{tabular}

$P$ values $<0.05$ after 10,000 permutations are bolded anti-microbial peptides in keratinocytes [11]. It has been proposed, that the primary cellular effect of IL-36 cytokines in psoriasis is their impact on neutrophil inflammation through activation of neutrophil chemokines CXCL1 and CXCL8 [33, 34]. Genetic studies have also lend support for the relevance of IL-36 family and have thus far focused on IL36RN. Different mutations in this gene, that caused substantial impairments in IL-36Ra protein, were associated with generalized pustular psoriasis, a rare and severe form of the disease [19-21]. Because our preceding findings implicated IL-36y as a primary suspect $[22,23]$, we decided to concentrate on its gene which is located $73 \mathrm{~kb}$ in $5^{\prime}$ direction from IL36RN.

The IL36G gene is located in the chromosomal region $2 \mathrm{q} 14.1$ together with the rest of IL-36 subfamily genes IL36A, IL36B and IL36RN. They all belong to the extended IL-1 family of cytokines and the genes of its five other members (IL1A,IL1B, IL37, IL1F10/IL38 and $I L 1 R N)$ surround the IL36 cluster. The length of IL36G is $7653 \mathrm{bp}$, containing 5 exons. Eleven SNPs were selected from the gene for the herein presented genetic association analysis that provided a number of statistically significant results. The strongest among them concerned SNPs rs28947206, rs28947207 and rs2894 7211 , which were associated in entire psoriasis analysis and also several subgroups. The first two SNPs were included in a haplotype block and its haplotypes CAGC and TGTT produced similarly significant associations. From the remaining SNPs, rs28947205, rs12328178 and rs34216066 were only associated in certain subgroup analyses. It should be noted, that many of the accompanying 95\% confidence intervals were large, albeit did not cross the value of 1 . This is due to the low frequencies of associated alleles and haplotypes and should be 
addressed in upcoming research by increasing the sample size.

To our knowledge, this is the first report describing IL36G variants in relation to psoriasis or any other condition. The physically closest SNP previously discussed is rs1374284 that was associated with therapy-related myeloid leukemia susceptibility and is located $10.3 \mathrm{~kb}$ from IL36G in 3' direction [35]. Since none of the associated SNPs affect the peptide sequence of IL-36y, they may exert regulatory control over IL36G expression or be in linkage disequilibrium with truly causal polymorphisms. In addition to transcription control, those causal variants could impact the conformation of IL-36y protein, thereby influencing its ability to bind to IL-36R and induce the downstream signals. Since proteolytic processing of IL-36y peptide is required to activate its proinflammatory activity [36,37], respective cleavage sites may also be affected. However, as mentioned above, the IL36G gene has not been thoroughly studied and possible functional polymorphisms have not been determined. Therefore, to confirm the significance of the genetic associations presented here, these precise mechanisms would have to be uncovered in future research.

\section{Conclusions}

Continuously accumulating evidence has suggested a role for IL-36y in psoriasis pathology and the objective of this study was to investigate, whether the variants of its gene could potentially be associated with the disease. For this purpose, eleven SNPs from IL36G region were genotyped in 728 plaque psoriasis patients and 320 healthy control individuals. The following statistical analyses resulted in three significantly associated SNPs and two haplotypes, while the remaining associations were more modest. This indicates that IL36G polymorphisms could possibly affect IL-36y functionality and thereby influence psoriasis susceptibility. The precise mechanisms are presently unknown and require respective experiments.

\section{Abbreviations \\ BSA: Body surface area; Cl: 95\% confidence interval; CXCL1: Chemokine (C-X- C motif) ligand 1; HWE: Hardy-Weinberg equilibrium; IFN-y: Interferon Y; IL: Interleukin; LL37: Cathelicidin; OR: Risk allele odds ratio; $p_{\text {adj: }}$ Multiple testing adjusted $p$ value; PASI: Psoriasis Area and Severity Index; SNP: Single- nucleotide polymorphism; Th17: T helper cell 17; TNF-a: Tumor necrosis factor a}

\section{Acknowledgements}

We would like to thank all patients and healthy volunteers for their participation.

\section{Funding}

This work was supported by personal research grant [PUT1465] from the Estonian Research Council and institutional research grant [IUT20-46] from the Estonian Ministry of Education and Research. The funders were not involved in study design or in collection, analysis, and interpretation of data or in writing of the manuscript.

\section{Availability of data and materials}

The datasets used and/or analysed during the current study are available from the corresponding author on reasonable request.

\section{Authors' contributions}

MKe, HS, SK and KK designed the study. TT, MKe, EP, MKa, UL and GK collected the blood samples and analysed the genotyping data. TT and MKe were primary participants in conducting statistical analyses. $\Pi$ drafted the initial manuscript and the remaining authors contributed in its revision. All authors have read and approved the manuscript.

\section{Ethics approval and consent to participate}

The Human Research Ethics Committee of the University of Tartu approved the study and written informed consent was obtained from all participants.

Consent for publication

Not applicable.

\section{Competing interests}

One of the authors, Sulev Kõks, is a member of the editorial board (Associate Editor) of this journal.

\section{Publisher's Note}

Springer Nature remains neutral with regard to jurisdictional claims in published maps and institutional affiliations.

\section{Author details}

'Department of Dermatology and Venerology, University of Tartu, 31 Raja St, 50417 Tartu, Estonia. ${ }^{2}$ Clinic of Dermatology, Tartu University Hospital, 31 Raja St, 50417 Tartu, Estonia. ${ }^{3}$ Department of Pathophysiology, University of Tartu, 19 Ravila St, 50411 Tartu, Estonia. ${ }^{4}$ Perron Institute, Murdoch University, 8 Verdun St, Perth, WA 6009, Australia.

Received: 11 July 2018 Accepted: 26 December 2018

Published online: 11 January 2019

References

1. Feldman SR, Malakouti M, Koo JY. Social impact of the burden of psoriasis: effects on patients and practice. Dermatol Online J. 2014;20.

2. Boehncke $W H$, Menter $A$. Burden of disease: psoriasis and psoriatic arthritis. Am J Clin Dermatol. 2013;14:377-88.

3. Parisi R, Symmons DP, Griffiths CE, Ashcroft DM. Global epidemiology of psoriasis: a systematic review of incidence and prevalence. J Invest Dermatol. 2013;133:377-85.

4. Boehncke WH, Schon MP. Psoriasis. Lancet. 2015;386:983-94.

5. Griffiths CE, Barker JN. Pathogenesis and clinical features of psoriasis. Lancet. 2007;370:263-71.

6. Liang Y, Sarkar MK, Tsoi LC, Gudjonsson JE. Psoriasis: a mixed autoimmune and autoinflammatory disease. Curr Opin Immunol. 2017;49:1-8.

7. Harden JL, Krueger JG, Bowcock AM. The immunogenetics of psoriasis: a comprehensive review. J Autoimmun. 2015:64:66-73.

8. Towne JE, Sims JE. IL-36 in psoriasis. Curr Opin Pharmacol. 2012;12:486-90.

9. Johnston A, Xing X, Guzman AM, Riblett M, Loyd CM, Ward NL, et al. IL-1F5, $-F 6$, -F8, and -F9: a novel IL-1 family signaling system that is active in psoriasis and promotes keratinocyte antimicrobial peptide expression. J Immunol. 2011;186:2613-22.

10. Blumberg $H$, Dinh $H$, Trueblood ES, Pretorius J, Kugler D, Weng N, et al. Opposing activities of two novel members of the IL-1 ligand family regulate skin inflammation. J Exp Med. 2007;204:2603-14.

11. Carrier $Y, M a ~ H L$, Ramon HE, Napierata L, Small C, O'Toole M, et al. Interregulation of Th17 cytokines and the $\mathrm{IL}-36$ cytokines in vitro and in vivo: implications in psoriasis pathogenesis. J Invest Dermatol. 2011;131:2428-37.

12. Blumberg H, Dinh H, Dean C Jr, Trueblood ES, Bailey K, Shows D, et al. IL$1 R L 2$ and its ligands contribute to the cytokine network in psoriasis. J Immunol. 2010;185:4354-62

13. Pfaff CM, Marquardt Y, Fietkau K, Baron JM, Luscher B. The psoriasisassociated IL-17A induces and cooperates with IL-36 cytokines to control keratinocyte differentiation and function. Sci Rep. 2017;7:15631.

14. Frohm M, Agerberth B, Ahangari G, Stahle-Backdahl M, Liden S, Wigzell H, et al. The expression of the gene coding for the antibacterial peptide $L L-37$ is 
induced in human keratinocytes during inflammatory disorders. J Biol Chem. 1997;272:15258-63.

15. Yamasaki K, Di Nardo A, Bardan A, Murakami M, Ohtake T, Coda A, et al. Increased serine protease activity and cathelicidin promotes skin inflammation in rosacea. Nat Med. 2007;13:975-80.

16. Ong PY, Ohtake T, Brandt C, Strickland I, Boguniewicz M, Ganz T, et al. Endogenous antimicrobial peptides and skin infections in atopic dermatitis. N Engl J Med. 2002;347:1151-60.

17. Furue K, Yamamura K, Tsuji G, Mitoma C, Uchi H, Nakahara T, et al. Highlighting Interleukin-36 Signalling in plaque psoriasis and pustular psoriasis. Acta Derm Venereol. 2018;98:5-13.

18. Li N, Yamasaki K, Saito R, Fukushi-Takahashi S, Shimada-Omori R, Asano M, et al. Alarmin function of cathelicidin antimicrobial peptide LL37 through IL-36gamma induction in human epidermal keratinocytes. J Immunol. 2014;193:5140-8.

19. Onoufriadis A, Simpson MA, Pink AE, Di Meglio P, Smith CH, Pullabhatla V, et al. Mutations in IL36RN/IL1F5 are associated with the severe episodic inflammatory skin disease known as generalized pustular psoriasis. Am J Hum Genet. 2011;89:432-7.

20. Sugiura K, Takeichi T, Kono M, Ogawa Y, Shimoyama Y, Muro Y, et al. A novel IL36RN/L1F5 homozygous nonsense mutation, p.Arg10X, in a Japanese patient with adult-onset generalized pustular psoriasis. Br J Dermatol. 2012;167:699-701.

21. Marrakchi S, Guigue P, Renshaw BR, Puel A, Pei XY, Fraitag S, et al. Interleukin-36-receptor antagonist deficiency and generalized pustular psoriasis. N Engl J Med. 2011;365:620-8.

22. Keermann M, Koks S, Reimann E, Prans E, Abram K, Kingo K. Transcriptional landscape of psoriasis identifies the involvement of IL36 and IL36RN. BMC Genomics. 2015;16:322.

23. Keermann M, Koks S, Reimann E, Abram K, Erm T, Silm H, et al. Expression of IL-36 family cytokines and IL-37 but not IL-38 is altered in psoriatic skin. J Dermatol Sci. 2015;80:150-2.

24. Koks S, Kingo K, Vabrit K, Ratsep R, Karelson M, Silm H, et al. Possible relations between the polymorphisms of the cytokines IL-19, IL-20 and IL-24 and plaque-type psoriasis. Genes Immun. 2005;6:407-15.

25. Barrett JC, Fry B, Maller J, Daly MJ. Haploview: analysis and visualization of LD and haplotype maps. Bioinformatics. 2005;21:263-5.

26. Hawkes JE, Chan TC, Krueger JG. Psoriasis pathogenesis and the development of novel targeted immune therapies. J Allergy Clin Immunol. 2017;140:645-53.

27. Oka A, Mabuchi T, Ozawa A, Inoko H. Current understanding of human genetics and genetic analysis of psoriasis. J Dermatol. 2012;39:231-41.

28. Lonnberg AS, Skov L, Skytthe A, Kyvik KO, Pedersen OB, Thomsen SF. Heritability of psoriasis in a large twin sample. Br J Dermatol. 2013;169:412-6.

29. Capon F, Burden AD, Trembath RC, Barker JN. Psoriasis and other complex trait dermatoses: from loci to functional pathways. J Invest Dermatol. 2012; 132:915-22.

30. Hebert HL, Ali FR, Bowes J, Griffiths CE, Barton A, Warren RB. Genetic sus. Oceptibility to psoriasis and psoriatic arthritis: implications for therapy. $\mathrm{Br} J$ Dermatol. 2012;166:474-82.

31. Yost J, Gudjonsson JE. The role of TNF inhibitors in psoriasis therapy: new implications for associated comorbidities. F1000 Med Rep. 2009;1.

32. Zaba LC, Cardinale I, Gilleaudeau P, Sullivan-Whalen M, Suarez-Farinas M, FuentesDuculan J, et al. Amelioration of epidermal hyperplasia by TNF inhibition is associated with reduced Th17 responses. J Exp Med. 2007;204:3183-94.

33. Foster AM, Baliwag J, Chen CS, Guzman AM, Stoll SW, Gudjonsson JE, et al. IL-36 promotes myeloid cell infiltration, activation, and inflammatory activity in skin. J Immunol. 2014;192:6053-61.

34. Lowes MA, Russell CB, Martin DA, Towne JE, Krueger JG. The IL-23/T17 pathogenic axis in psoriasis is amplified by keratinocyte responses. Trends Immunol. 2013;34:174-81.

35. Knight JA, Skol AD, Shinde A, Hastings D, Walgren RA, Shao J, et al. Genome-wide association study to identify novel loci associated with therapy-related myeloid leukemia susceptibility. Blood. 2009;113:5575-82.

36. Henry CM, Sullivan GP, Clancy DM, Afonina IS, Kulms D, Martin SJ. Neutrophil-derived proteases escalate inflammation through activation of IL-36 family cytokines. Cell Rep. 2016;14:708-22.

37. Ainscough JS, Macleod T, McGonagle D, Brakefield R, Baron JM, Alase A, et al. Cathepsin $\mathrm{S}$ is the major activator of the psoriasis-associated proinflammatory cytokine IL-36gamma. Proc Natl Acad Sci U S A. 2017;114:E2748-E57.

\section{Ready to submit your research? Choose BMC and benefit from:}

- fast, convenient online submission

- thorough peer review by experienced researchers in your field

- rapid publication on acceptance

- support for research data, including large and complex data types

- gold Open Access which fosters wider collaboration and increased citations

- maximum visibility for your research: over $100 \mathrm{M}$ website views per year

At $\mathrm{BMC}$, research is always in progress.

Learn more biomedcentral.com/submissions 